\title{
Voluntary eyeblinks disrupt iconic memory
}

\author{
LAURA E. THOMAS and DAVID E. IRWIN \\ University of Illinois at Urbana-Champaign, Urbana, Illinois
}

\begin{abstract}
In the present research, we investigated whether eyeblinks interfere with cognitive processing. In Experiment 1, the participants performed a partial-report iconic memory task in which a letter array was presented for $106 \mathrm{msec}$, followed 50, 150, or $750 \mathrm{msec}$ later by a tone that cued recall of one row of the array. At a cue delay of $50 \mathrm{msec}$ between array offset and cue onset, letter report accuracy was lower when the participants blinked following array presentation than under no-blink conditions; the participants made more mislocation errors under blink conditions. This result suggests that blinking interferes with the binding of object identity and object position in iconic memory. Experiment 2 demonstrated that interference due to blinks was not due merely to changes in light intensity. Experiments 3 and 4 demonstrated that other motor responses did not interfere with iconic memory. We propose a new phenomenon, cognitive blink suppression, in which blinking inhibits cognitive processing. This phenomenon may be due to neural interference. Blinks reduce activation in area V1, which may interfere with the representation of information in iconic memory.
\end{abstract}

Eyeblinks, transient closures and reopenings of the eyes, occur every few seconds for a variety of reasons. Humans may blink the eyes reflexively in response to a loud noise, a puff of air, or a flash of light, they may blink voluntarily in response to external or internal commands, or they may blink spontaneously through central, involuntary programming. Regardless of how or why a blink occurs, all eyeblinks are associated with a loss of visual information as the eyelid obscures the pupil. Interestingly, although the pupil is completely covered by the eyelid for approximately $100 \mathrm{msec}$ during a blink, people typically do not consciously experience a visual disruption, even though a similar degradation of ambient light due to external sources is readily noticeable (Volkmann, Riggs, \& Moore, 1980).

In their investigation of why this blanking of the visual world goes unnoticed during eyeblinks, Volkmann et al. (1980) provided stimulation to the retina through the back of the eyeball via a fiber-optic bundle placed against the roof of the mouth. The researchers found that visual sensitivity to this light was reduced before, during, and after blinking, even though the light source was never physically interrupted by a blink. The results of their study showed that visual suppression associated with eyeblinks is at least partly a result of a neural, rather than optical, inhibitory mechanism. Neurophysiological data support this conclusion; recordings taken from V1 show that neurons are essentially shut off during a blink (Gawne \& Martin, 2000).

This research was supported by NSF Grant BCS 01-32292. The authors thank Ron Rensink and two anonymous reviewers for their helpful comments on an earlier version of the manuscript and Benjamin Johnson, Scott Dalton, Richard Carlson, and Nancy Wai for their assistance in data collection. Correspondence should be addressed to L. E. Thomas, Department of Psychology, University of Illinois, 603 E. Daniel St., Champaign, IL 61820 (e-mail: lethomas@s.psych.uiuc.edu).
The visual suppression that accompanies a blink has consequences for certain cognitive tasks. In an attempt to minimize the probability of missing important information, people reduce their rate of blinking during a visually demanding task (Baumstimler \& Parrot, 1971; Drew, 1951; Kennard \& Glaser, 1964; Stern \& Skelly, 1984). Blinks can also reflect the cognitive demands of a task, irrespective of its visual demands; people blink less often when engaged in a task that taxes cognitive resources (Stern, Walrath, \& Goldstein, 1984). In addition, researchers have suggested that certain characteristics of blinks, such as latency, can be used as an index of the level of complexity in an information-processing task (Fogarty \& Stern, 1989).

Although this previous research has shown that thinking can affect blinking, it is still unclear whether the reciprocal relationship is also true. Does blinking affect thinking? Since vision is suppressed by neural mechanisms during a blink, it is possible that blinking may also suppress cognitive processing. Another kind of eye movement, saccadic eye movement, which shares neural characteristics with blinks (Ridder \& Tomlinson, 1995, 1997; Uchikawa \& Sato, 1995; Volkmann, 1986), has been shown to suppress some cognitive processes (e.g., Brockmole, Carlson, \& Irwin, 2002; Irwin \& Brockmole, 2000, 2004; Irwin \& Carlson-Radvansky, 1996), so eyeblinks may have similar effects. This question is an important one because blinks occur on average once every $4 \mathrm{sec}$, or 900 times per hour, and the average blink duration is approximately $250 \mathrm{msec}$; thus, a total of $1 \mathrm{~h}$ out of every 16 -h waking day is spent blinking, time during which cognitive processing may be hindered. In the present study, we examined whether performing an eyeblink does in fact interfere with the performance of a cognitive task.

To address this question, we examined a task in which it seemed likely that eyeblinks might interfere with perfor- 
mance-an iconic memory task. In particular, we investigated accuracy of recall from a briefly presented array under blink and no-blink conditions. In this task, the participants saw an array of letters, then heard an auditory cue indicating which part of the array should be reported. This kind of partial-report procedure has long been used as a measure of iconic memory (e.g., Sperling, 1960). Because iconic memory decays rapidly, accuracy of report declines quickly as the interval between array offset and response cue increases. Although iconic memory was once thought to be a visible, precategorical, high-capacity, literal copy of a stimulus (e.g., Neisser, 1967), more recent research has shown that the partial-report paradigm measures both precategorical and postcategorical (i.e., cognitive) sources of information (Coltheart, 1980; Di Lollo, 1978; Loftus \& Irwin, 1998). For example, in several studies, it has been shown that most errors in partial report tasks are mislocation errors, rather than item intrusion errors (e.g., Dick, 1969; Irwin \& Yeomans, 1986; Townsend, 1973); that is, erroneous responses are much more likely to involve report of a letter that had appeared somewhere in the array, rather than a letter that was not present. Furthermore, familiarity with the letter array has been found to reduce the number of intrusion, but not mislocation, errors (Mewhort, Campbell, Marchetti, \& Campbell, 1981). These results indicate that the partial-report procedure accesses a postcategorical store in which array items are identified and remembered quite well, but their locations are forgotten. Because partial-report performance reflects the intersection of perceptual processing and cognitive processing, investigating the effects of eyeblinks on partial-report performance seemed to be an ideal starting point for research on the potential inhibitory effects of blinking on cognitive processing.

\section{EXPERIMENT 1}

In Experiment 1, the participants were briefly shown a $3 \times 3$ array of letters, followed by one of three cue delays and then by a cue tone and a response prompt. Depending on the pitch of the tone, the participants attempted to recall the top, the middle, or the bottom row of the array. On some trials, the participants were told to blink as soon as they saw the array; on other trials, they were told to keep their eyes open and fixated. The latency of voluntary blinks exceeded the duration of the stimulus array by over $100 \mathrm{msec}$, so the blink did not prevent the participants from seeing the array. Therefore, any differences in performance on the partial-report task between blink and no-blink conditions would provide an indication that blinking disrupts the maintenance of stimulus information in memory. Varying the cue delay between the offset of the letter array and the onset of the partial-report cue tone allowed an investigation of the time course of interference. Because iconic memory typically decays away within $250 \mathrm{msec}$ of stimulus offset, performance at short cue delays should be worse in the blink condition than in the no-blink condition if blinks interfere with iconic memory. At cue delays longer than $250 \mathrm{msec}$, participants rely on a more durable memory store, short-term memory, instead of iconic memory to complete the partial-report task (e.g., Sperling, 1963). Thus, differences in performance at long cue delays between blink and no-blink conditions would suggest that blinking disrupts short-term memory.

\section{Method}

Participants. Twelve students at the University of Illinois participated in one experimental session approximately $60 \mathrm{~min}$ long. All participants reported normal or corrected-to-normal vision and were naive with respect to the experimental hypotheses. They received $\$ 6$ per hour for their participation.

Stimuli. The stimuli consisted of randomly generated $3 \times 3$ arrays of uppercase letters. No vowels were used in the stimulus set.

Apparatus. Stimuli were presented on a 21 -in. monitor with resolution of $800 \times 600$ pixels and a refresh rate of $85 \mathrm{~Hz}$. Eye movements and blinks were recorded with an EyeLink II videobased eyetracker (SR Research, Mississauga, Ontario) with temporal resolution of $500 \mathrm{~Hz}$, spatial resolution of $0.1^{\circ}$, and pupil-size resolution of $0.1 \%$ of pupil diameter. An eye movement was classified as a saccade when its distance exceeded $0.2^{\circ}$ and its velocity reached $30^{\circ} / \mathrm{sec}$ or when its distance exceeded $0.2^{\circ}$ and its acceleration reached $9,500^{\circ} / \mathrm{sec}^{2}$. The eyetracker classified movements of the eyelids that occluded the pupil for at least 6 sequential milliseconds as eyeblinks.

During the experiment, the participants were seated $48 \mathrm{~cm}$ from the display monitor, where their heads were stabilized by a chinrest. At this viewing distance, the $3 \times 3$ letter array subtended approximately $3.6^{\circ}$ of visual angle horizontally and $4.7^{\circ}$ vertically. Individual letters subtended approximately $0.8^{\circ}$ horizontally and $1.2^{\circ}$ vertically. The circular calibration/drift correction dot presented at the start of each trial subtended $0.6^{\circ}$. The display background was light gray (luminance $=86.3 \mathrm{~cd} / \mathrm{m}^{2}$ ), and all stimuli were black (luminance $=6.5 \mathrm{~cd} / \mathrm{m}^{2}$ ). The participants entered their partial-report responses using a standard computer keyboard.

Procedure. Figure 1 shows the events that occurred during a partial-report trial in the no-blink condition. Each trial began with a drift correction procedure in which the participants fixated a dot in the center of the display and pressed the return key. Following successful drift correction, a blank screen was presented for $500 \mathrm{msec}$ in order to prevent visual masking by the drift correction dot. After this delay, the $3 \times 3$ array was presented for $106 \mathrm{msec}$, followed 50, 150 , or $750 \mathrm{msec}$ later by a cue tone with a duration of $150 \mathrm{msec}$. One second after the tone, a response prompt appeared, and the participants were asked to type three letters. On the basis of the pitch of the cue tone (high, medium, or low), the participants reported the top, the middle, or the bottom row of letters, respectively. There was no time limit on responding. Once the participants were satisfied with their responses, they pressed the "return" key, and feedback was provided in the center of the display for $1,000 \mathrm{msec}$, indicating correct responses with a "+" and incorrect responses with a "-." The next trial began after this feedback was provided.

Trials in the blink condition were identical to trials in the no-blink condition, with one exception: The participants were instructed to perform a voluntary eyeblink as soon as the letter array appeared. Figure 2 helps conceptualize how blinks fit into the temporal ordering of these trials. The average latency of voluntary blinks in this experiment was $225 \mathrm{msec}$, and the average blink duration was $265 \mathrm{msec}$. Because the duration of the letter array was $106 \mathrm{msec}$, on average the blink was initiated $119 \mathrm{msec}$ after the offset of the letter array. For trials in which the cue delay between array offset and cue tone onset was $50 \mathrm{msec}$, this meant that the blink was initiated during the sounding of the cue tone and ended after tone offset. In the 150 -msec cue delay condition, blink initiation and cue tone onset occurred close together in time, with the blink ending shortly after the tone. The blink was initiated and terminated before the tone was ever presented for trials in which the cue delay was $750 \mathrm{msec}$. 


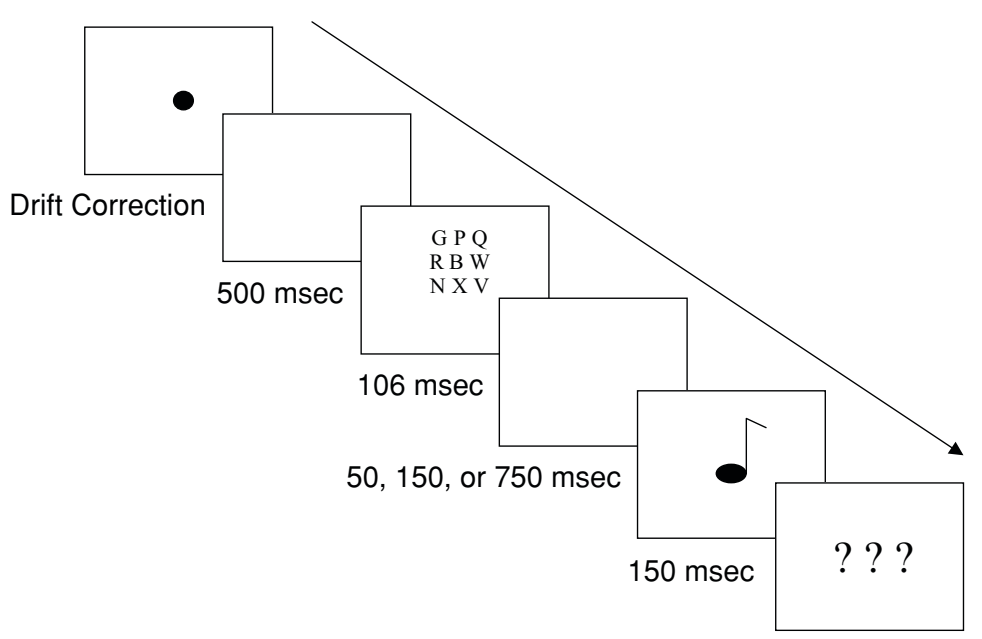

Figure 1. Sequence of events for a no-blink partial-report trial.

Before completing the blink and no-blink partial report trials, the participants completed practice trials to help them learn to discriminate the three tones used as cues in the partial-report experiment. Each of these trials consisted of sounding one of the cue tones for $150 \mathrm{msec}$, followed by a response prompt. The participants indicated the pitch of the tone they had just heard by typing a number $(1,2$, or 3$)$ corresponding to a high-, a medium-, or a low-pitched tone, respectively. Following a response, feedback was provided for $1,000 \mathrm{msec}$ before a new trial began.

Design. The participants first practiced discriminating the cue tones used in the partial-report trials. The tones were presented in descending order 10 times in a row. The participants then completed 54 tone discrimination trials. If accuracy on this task was below $90 \%$, an additional block of tone practice trials was run. One participant was unable to achieve $90 \%$ accuracy in the tone discrimination task after two rounds of practice, was dropped from the study, and was replaced.

Following successful completion of the tone discrimination task, the participants completed two blocks of 36 practice partial-report trials. For these trials, the participants were instructed not to blink. If response accuracy for the final block of trials fell below $60 \%$ for the $50-\mathrm{msec}$ cue delay condition or below $30 \%$ for the $750-\mathrm{msec}$ cue delay condition, the participant completed another two blocks of partial-report practice trials. Three participants whose accuracies still fell below criterion after this additional round of practice were dropped from the study and were replaced.

Once the participants successfully completed the practice trials, they were fitted with the eyetracker, and a calibration procedure was run. They then completed three blocks of 36 trials in the no-blink partialreport condition and three blocks of 36 trials in the blink condition. The pitch of the cue tone was sequenced randomly across trials, with each row being indicated 12 times in each block. The cue delay between array offset and cue onset was also sequenced randomly across trials, with each cue delay occurring 12 times in each block. The pitch of the cue tone and the cue delay were counterbalanced in each block, such that each combination of cue tone and cue delay occurred four times in each block of 36 trials. The first block in each set of three blocks was designated as practice, and data for these blocks were not analyzed. A written prompt appeared for 2,000 msec at the beginning of each block that instructed the participants whether or not to blink during the trials in that block. The ordering of conditions was counterbalanced, with half of the participants completing the no-blink condition first, and the other half completing the blink condition first.

\section{Results and Discussion}

No-blink trials in which the participants performed a blink were eliminated from analyses, as were blink trials

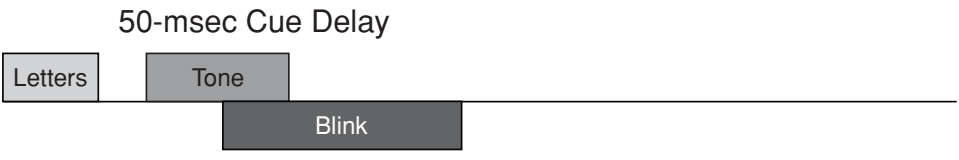

150-msec Cue Delay

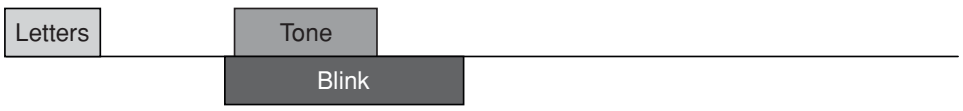

750-msec Cue Delay

Figure 2. Temporal order of events on blink partial-report trials at 50-, 150-, and 750-msec cue delays. 
in which the participants did not blink or in which the blink was initiated before array offset or had a latency of over $500 \mathrm{msec}$. A total of $5.0 \%$ of no-blink trials and a total of $17.8 \%$ of blink trials were discarded. For the remaining trials in the blink condition, mean blink latencies were $215 \mathrm{msec}$ when the cue delay was $50 \mathrm{msec}, 233 \mathrm{msec}$ when the cue delay was $150 \mathrm{msec}$, and $227 \mathrm{msec}$ when the cue delay was $750 \mathrm{msec}$. The main effect of cue delay was significant in a one-way ANOVA $\left[F(2,22)=6.7, M S_{\mathrm{e}}=\right.$ $157, p=.005]$. A Scheffé $95 \%$ confidence interval showed that pairwise differences greater than $13.4 \mathrm{msec}$ were significant, indicating that blink latency when the cue delay was $150 \mathrm{msec}$ was significantly longer than when the cue delay was $50 \mathrm{msec}$; no other comparisons were significant. Since the participants did not know from one trial to the next what the cue delay would be and since blinks must have been programmed well in advance of tone onset, it seems likely that this effect was due to random variation. Blink duration did not vary as a function of cue delay $\left[F(2,22)=1.3, M S_{\mathrm{e}}=2,050, p>.25\right]$. The mean blink durations were $276 \mathrm{msec}$ at a cue delay of $50 \mathrm{msec}$, $271 \mathrm{msec}$ at a cue delay of $150 \mathrm{msec}$, and $248 \mathrm{msec}$ at a cue delay of $750 \mathrm{msec}$.

The primary question under investigation was whether partial-report performance differed between the blink and no-blink conditions. Three measures of performance on the partial-report task were examined. First, the percentages of correct responses were calculated for both blink and no-blink conditions at each of the three cue delays. A response was classified as correct if the participant reported the correct letter in the correct position in the array. Next, errors were separated into two groups. A mislocation error occurred when the participant reported a letter that had been present in the array but not in the position that he/she indicated. An intrusion error occurred when the participants reported a letter that was not present in the array. If performing a blink interferes with memory for the letter array, then the participants should give fewer correct responses in the blink condition than in the noblink condition; this effect may be limited to only short cue delays if blinking affects only iconic memory and not more durable memory stores. The distribution of mislocation and intrusion errors between conditions provides information about the nature of the interference; intrusion errors are typically thought to arise from the loss of item identity information in memory, whereas mislocation errors arise when location information is not bound to item identity information (e.g., Dick, 1969; Irwin \& Yeomans, 1986; Mewhort et al., 1981; Townsend, 1973).

Figure 3 shows the mean percentage of correct responses, mislocation errors, and intrusion errors in the blink and no-blink conditions as a function of cue delay. Separate two-way ANOVAs with factors of condition (blink vs. noblink) and cue delay were conducted on each dependent measure. The results for correct responses are considered first. As can be seen from the figure, the participants were generally less accurate in their partial-report performance as the interval between the array and cue tone increased, which would be expected in the standard partial-report paradigm (e.g., Averbach \& Coriell, 1961; Sperling, 1960). This decreasing trend in accuracy as a function of increasing cue delay was reflected in a significant main effect of cue delay $\left[F(2,22)=24.4, M S_{\mathrm{e}}=0.011, p<.001\right]$. Of greater interest is the fact that there was a significant main effect of condition $\left[F(1,11)=11.0, M S_{\mathrm{e}}=0.005, p=\right.$ $.007]$, as well as a significant interaction between con-

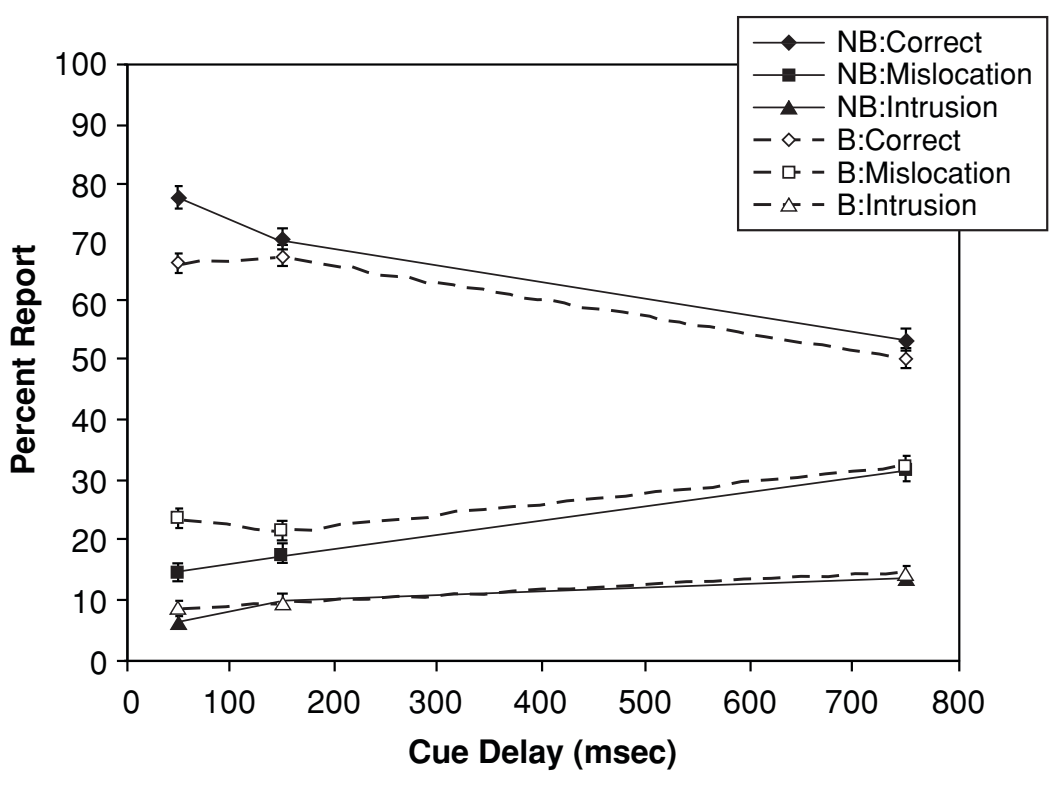

Figure 3. Mean percentages of correct responses, mislocation errors, and intrusion errors as a function of cue delay for no-blink (NB) and blink (B) trials in Experiment 1. 
dition type and cue delay $\left[F(2,22)=3.5, M S_{\mathrm{e}}=0.004\right.$, $p<.05]$. The error term for this interaction was used to construct a $95 \%$ confidence interval for comparing two means; differences greater than $4.8 \%$ were significant. Thus, the interaction occurred because there was a significant difference in accuracy between the no-blink condition $(77.7 \%)$ and the blink condition (66.5\%) at the $50-\mathrm{msec}$ cue delay, but not at the 150 -msec cue delay $(71.3 \%$ vs. $68.4 \%$ ) or the 750 -msec cue delay (53.8\% vs. $51.4 \%$ ). The accuracy data therefore suggest that blinking disrupts iconic memory but does not interfere with more durable memory stores.

In order to better understand the nature of this disruption, we examined the types of errors that occurred in the blink and no-blink conditions. Separate two-way ANOVAs with factors of condition and cue delay were conducted on the mean percentages of mislocation errors and intrusion errors. Examination of Figure 3 shows that the participants were much more likely to make mislocation errors than intrusion errors in either condition, and both types of errors increased as cue delay increased [for mislocation errors, $F(2,22)=17.8, M S_{\mathrm{e}}=0.007, p<.001$; for intrusion errors, $\left.F(2,22)=18.6, M S_{\mathrm{e}}=0.001, p<.001\right]$. There were no differences in the percentage of intrusion errors between blink and no-blink conditions, nor did condition type and cue delay interact $(p s>3)$. The lower accuracy in partial-report performance for the blink condition at the shortest cue delay was therefore not a result of more intrusion errors, as can be seen from Figure 3, but rather was due to an increase in the number of mislocation errors committed when the participants blinked during a trial. There were significantly more mislocation errors under the blink condition than under the no-blink condition $\left[F(1,11)=8.7, M S_{\mathrm{e}}=0.004, p=.01\right]$, and the interaction between condition and cue delay was marginally significant $\left[F(2,22)=3.2, M S_{\mathrm{e}}=0.003, p<.06\right]$. The error term for this interaction was used to construct a $95 \%$ confidence interval for comparing two means, and this showed that differences greater than $4.2 \%$ were significant. Thus, there were significantly more mislocation errors at the 50-msec cue delay for the blink condition $(24.2 \%)$ than for the no-blink condition (15.0\%), but there was no difference between conditions at the $150-\mathrm{msec}$ cue delay ( $22.2 \%$ vs. $18.3 \%$ ) or at the 750 -msec cue delay ( $33.1 \%$ vs. $32.2 \%)$. The tendency for the participants to make more mislocation errors in the blink condition than in the no-blink condition suggests that blinks interfere with the binding of object identity with object position in iconic memory. In other words, the participants were able to recall which letters they had seen, but they were unable to remember where these letters had been located within the array.

In sum, the results of Experiment 1 showed that blinking disrupts iconic memory, providing the first evidence that blinking interferes with at least one kind of cognitive processing. In particular, blinks appear to interfere with the binding of object identity information with object position information. Could the detrimental effects of blinking be due instead to a reduction in the visual quality of the letter array? That is, perhaps blinks interfere with the perception of the letter array, as opposed to iconic memory for the array. This seems unlikely for three reasons. First, the onset of the letter array in Experiment 1 preceded blink onset by $225 \mathrm{msec}$ on average, and the reduction in visual sensitivity associated with blinks is minimal at this separation (Volkmann et al., 1980). Second, if the difference in partial-report performance between the blink and no-blink conditions was due to differences in the physical visual quality of the stimulus, then a performance decrement should have been seen for all three cue delays in the blink condition, instead of only at the 50 -msec cue delay. Third, the fact that the accuracy reduction at the 50-msec cue delay was accompanied by an increase in mislocation errors rather than intrusion errors suggests that it was the binding of letter identity with letter position that was disrupted by blinking, rather than letter identification per se.

In Experiments 2-4, in order to strengthen the conclusion that blinks interfere with cognitive processing, we sought to rule out some possible alternative explanations for the results of Experiment 1. For example, it is possible that purely visual events surrounding an eyeblink, rather than blink-induced cognitive suppression, interfere with partial-report performance. It is well known that iconic memory is sensitive to visual masking. During a blink, the eyelids act as a filter, greatly reducing the amount of light reaching the retina. When the eyes reopen after a blink, the rapid increase in light reaching the retina may mask the icon and interfere with partial-report performance. Previous research has shown that masking increases mislocation errors more than intrusion errors in partial report (e.g., Irwin \& Brown, 1987; Irwin \& Yeomans, 1986), consistent with the effects of blinks in Experiment 1. We examined this purely visual account of the blink effect in Experiment 2. Another possible explanation for the results of Experiment 1 is that any extraneous motor response, and not just eyeblinks, interferes with partial-report performance. We examined this in Experiments 3 and 4.

\section{EXPERIMENT 2}

In Experiment 2, we investigated to what extent the detrimental effect of blinking on iconic memory was due to purely visual events surrounding an eyeblink, rather than to the eyeblink itself. Two groups of participants performed the same partial report task that was used in Experiment 1 under two conditions. In the no-mask condition, the participants performed the normal partial-report task with continuously open eyes; this condition was essentially a replication of the no-blink condition of Experiment 1. In the mask conditions, however, we attempted to mimic the visual effects of a blink on screen while the participants kept their eyes open. For one group of participants (the total-blackout group), the display changed from light gray to black at the time corresponding to average blink onset in Experiment 1 (approximately $225 \mathrm{msec}$ after display onset) and stayed black for the average duration of blinks in Experiment 1 (approximately $265 \mathrm{msec}$ ) before changing 
back to light gray. Perceptually, this manipulation was very unlike a real eyeblink, being both longer in total blackout duration and more severe in terms of the luminance decrement (as discussed in the introduction, the perceptual effects of real eyeblinks are minimized by visual suppression, which was absent in our total-blackout manipulation). Although perceptually dissimilar to an eyeblink, this manipulation may still provide a useful estimate of the largest possible masking effect associated with blinking. For the other group of participants (the simulated-blink group), we attempted to match the subjective magnitude of a real eyeblink, on the basis of research by Riggs, Volkmann, and Moore (1981). These investigators asked participants to compare the visual effect of various luminance decrements (while the eyes were open) with that generated by eyeblinks to determine the subjectively equivalent light decrement associated with blinking. They found that light decrements that were perceived to be subjectively equivalent to eyeblinks had a smaller magnitude and a shorter duration than the physical values actually generated by an eyeblink (which, of course, provides additional evidence that visual input is suppressed during eyeblinks). On the basis of their findings, we used a luminance decrement of $40 \%$ (slightly more than the average matching decrement reported by their participants at the highest luminance level they investigated) for $125 \mathrm{msec}$ in our simulated-blink group. It was our sense that this decrement was still somewhat more noticeable than that associated with eyeblinks, perhaps because only the display monitor "blinked" in our case, whereas the rest of the environment did not (Riggs et al. presented their decrements in a Ganzfeld, so the entire environment "blinked" in their study). Riggs et al. also used ramped onsets and offsets for their simulated blinks, whereas ours were discrete; thus, in our case, there was a noticeable transient at the beginning and the end of each simulated blink. Note that the effect of this was to bias our simulated-blink manipulation in favor of the visual masking account of the results of Experiment 1, rather than the blink-induced cognitive suppression hypothesis that we favor (i.e., we erred on the side of caution).

If the interference we observed in Experiment 1 was a result of visual events surrounding eyeblinks, rather than the result of eyeblinks per se, then we expected to observe a pattern of interference in the mask conditions of Experiment 2 similar to that in the blink condition of Experiment 1. However, if the blink interference was due to blink-induced suppression of cognitive processing instead, then we would expect to find a pattern of results in the mask conditions of Experiment 2 different from that in the blink condition of Experiment 1.

\section{Method}

Participants. Twenty-two students at the University of Illinois participated: 10 in the total-blackout group, and 12 in the simulatedblink group. Each participant completed one experimental session approximately $60 \mathrm{~min}$ long. All participants reported normal or corrected-to-normal vision, were naive with respect to the experimental hypotheses, and had not participated in Experiment 1. They received \$6 per hour for their participation.
Stimuli and Apparatus. The stimuli and apparatus for Experiment 2 were identical to those described for Experiment 1.

Procedure. The sequence of events in the no-mask trials was identical to that of the no-blink trials of Experiment 1. That is, a $3 \times 3$ array of letters was presented for $106 \mathrm{msec}$, followed 50, 150, or $750 \mathrm{msec}$ later by a tone that cued report of one row of the array. The display background had a luminance of $86.3 \mathrm{~cd} / \mathrm{m}^{2}$ throughout these trials. On the mask trials, the luminance of the display background decreased $223 \mathrm{msec}$ after array onset. For the total-blackout group, the display background decreased to $6.5 \mathrm{~cd} / \mathrm{m}^{2}$ for $270 \mathrm{msec}$ before increasing back to $86.3 \mathrm{~cd} / \mathrm{m}^{2}$. For the simulated-blink group, the display background decreased to $51.8 \mathrm{~cd} / \mathrm{m}^{2}$ for $129 \mathrm{msec}$ before increasing back to $86.3 \mathrm{~cd} / \mathrm{m}^{2}$. The participants were instructed to keep their eyes open for the entire duration of a mask trial. All other aspects of the mask trials were the same as those of the no-mask trials.

Design. The design of Experiment 2 was identical to the design of Experiment 1; the same sequence and number of tone discrimination and partial-report practice trials were included. The participants performed three blocks of 36 trials in the no-mask condition and three blocks of 36 trials in the mask condition, with the first block of trials in each condition used as practice. Counterbalancing between conditions was the same as that for Experiment 1.

\section{Results and Discussion}

Figure 4 shows the mean percentage of correct responses, mislocation errors, and intrusion errors for the no-mask and mask conditions as a function of cue delay for the total-blackout group. Two-way ANOVAs with factors of condition (no-mask vs. mask) and cue delay were conducted separately on all three measures. For correct responses, the main effect of condition was significant $\left[F(1,9)=16.1, M S_{\mathrm{e}}=0.004, p<.005\right]$, as was the main effect of cue delay $\left[F(2,18)=44.0, M S_{\mathrm{e}}=0.003, p<\right.$ $.001]$. However, the interaction between these variables was not significant $\left[F(2,18)=0.3, M S_{\mathrm{e}}=0.004, p>.7\right]$. Thus, the mask for the total-blackout group lowered accuracy at all three cue delays, unlike the results of Experiment 1 , in which blinks lowered accuracy only at the shortest cue delay. Similar results were obtained in the analysis of the mislocation errors. The main effect of condition was marginally significant $\left[F(1,9)=4.9, M S_{\mathrm{e}}=0.005\right.$, $p<.06]$, and the main effect of cue delay was significant $\left[F(2,18)=6.2, M S_{\mathrm{e}}=0.004, p<.01\right]$, but the interaction between these variables was not significant $[F(2,18)=$ $\left.0.2, M S_{\mathrm{e}}=0.002, p>.8\right]$. So, whereas blinks in Experiment 1 increased mislocation errors only at the shortest cue delay, the mask used for the total-blackout group in Experiment 2 increased mislocation errors at all cue delays. For intrusion errors, the main effect of condition was significant $\left[F(1,9)=6.7, M S_{\mathrm{e}}=0.002, p<.03\right]$, as was the main effect of cue delay $\left[F(2,18)=58.5, M S_{\mathrm{e}}=\right.$ $0.001, p<.001]$, but the interaction between these variables was not significant $\left[F(2,18)=1.3, M S_{\mathrm{e}}=0.002\right.$, $p>$.25]. In Experiment 1, there was no difference in the number of intrusion errors between the blink and no-blink conditions at any cue delay. In sum, the mask used for the total-blackout group in Experiment 2 produced effects on performance that were quite different from those produced by eyeblinks in Experiment 1. The mask was disruptive at all cue delays and increased intrusion errors and mislocation errors. 


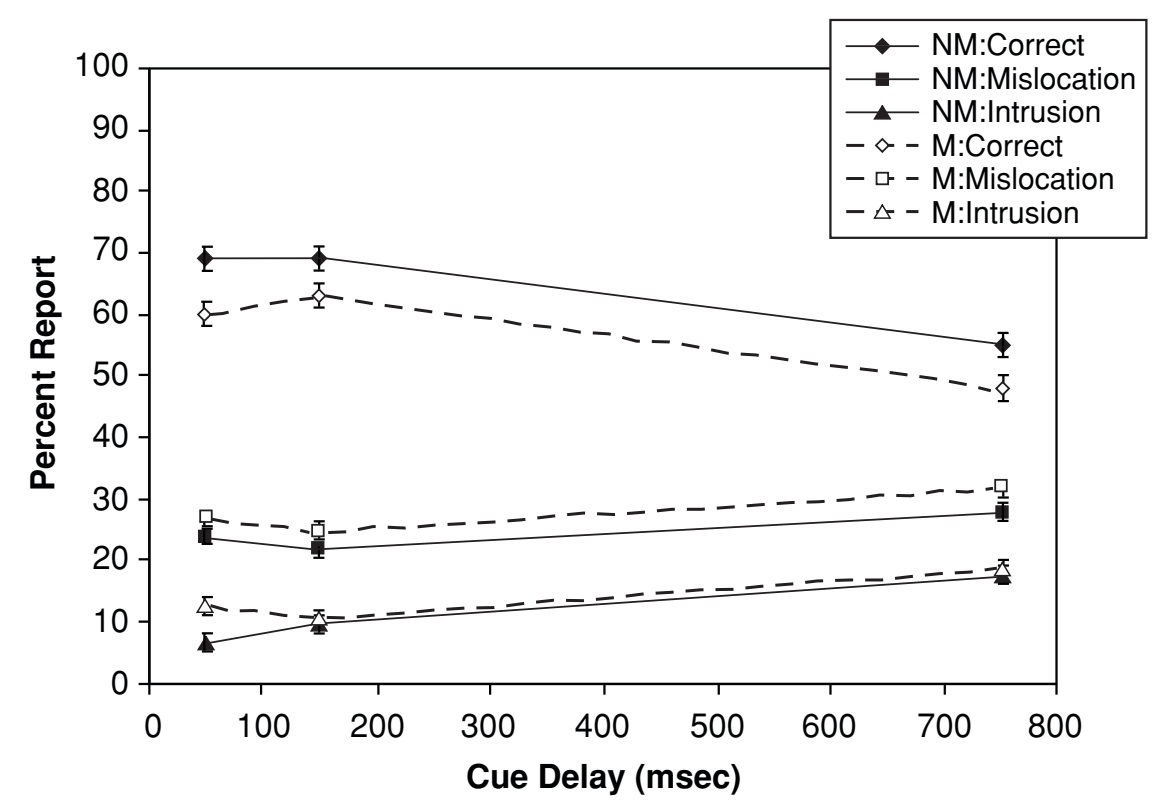

Figure 4. Mean percentages of correct responses, mislocation errors, and intrusion errors as a function of cue delay for no-mask (NM) and mask (M) trials for the total-blackout group in Experiment 2.

The mask used for the simulated-blink group was designed to be much more similar perceptually to the visual events associated with eyeblinks. The results for this group are shown in Figure 5. Two-way ANOVAs with factors of condition (no-mask vs. mask) and cue delay were conducted separately on correct responses, mislocation errors, and intrusion errors. Only the main effect of cue delay was significant in these analyses [for correct responses, $F(2,22)=57.0, M S_{\mathrm{e}}=0.006, p<.001$; for mislocation errors, $F(2,22)=17.4, M S_{\mathrm{e}}=0.006, p<$ .001 ; for intrusion errors, $F(2,22)=18.9, M S_{\mathrm{e}}=0.003$, $p<.001]$. The main effect of condition was not significant in any analysis [for correct responses, $F(1,11)=2.2$, $M S_{\mathrm{e}}=0.005, p>.15$; for mislocation errors, $F(1,11)=$

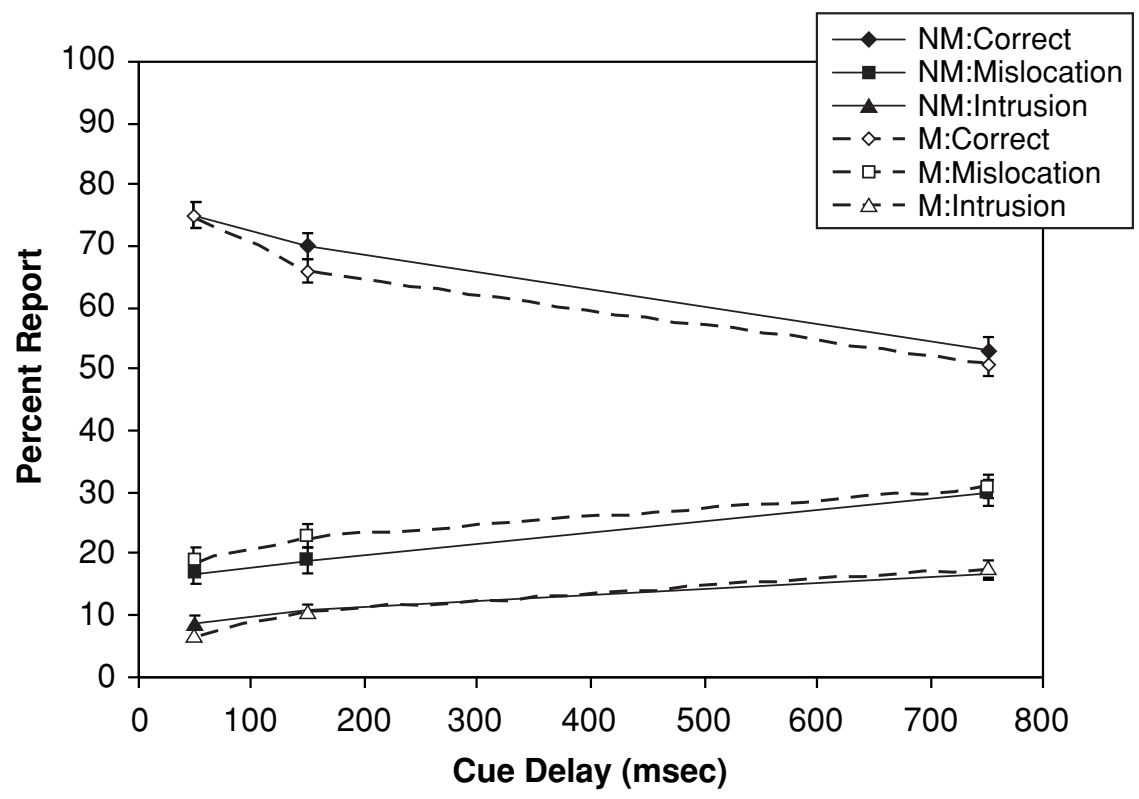

Figure 5. Mean percentages of correct responses, mislocation errors, and intrusion errors as a function of cue delay for no-mask (NM) and mask (M) trials for the simulated-blink group in Experiment 2. 
$3.9, M S_{\mathrm{e}}=0.003, p>.07$; for intrusion errors, $F(1,11)=$ $\left.0.01, M S_{\mathrm{e}}=0.002, p>.9\right]$, nor were there any significant interactions between condition and cue delay [for correct responses, $F(2,22)=0.7, M S_{\mathrm{e}}=0.004, p>.4$; for mislocation errors, $F(2,22)=0.4, M S_{\mathrm{e}}=0.005, p>.6$; for intrusion errors, $F(2,22)=1.2, M S_{\mathrm{e}}=0.001, p>$.3]. In sum, for the simulated-blink group, performance on the partial-report task was the same regardless of whether or not a mask (simulated blink) was presented.

If purely visual factors associated with blinking caused the decrement in performance observed in Experiment 1, then we should have seen similar decrements in performance in the mask conditions of Experiment 2, which attempted to mimic the visual events surrounding an eyeblink. However, neither mask used in Experiment 2 produced results like those produced by eyeblinks in Experiment 1 . Therefore, we conclude that the interference observed in Experiment 1 was not due to visual events surrounding the eyeblink but rather was due to something specific to eyeblinks themselves. In particular, eyeblinks appear to interfere with the binding of location and identity information in memory.

But are blinks special in their ability to disrupt iconic memory? Perhaps any extraneous motor response might interfere with partial report performance. We examined this in Experiments 3 and 4.

\section{EXPERIMENT 3}

In Experiment 3, we examined whether or not motor responses besides blinking interfere with partial-report performance. The participants performed the same partialreport task that was used in Experiment 1 under singleand dual-task conditions. In contrast to Experiment 1, where the dual-task condition involved the participants' blinking as soon as they saw the letter array, in Experiment 3 , the participants were told to press a button on a handheld response device when the letter array appeared. If any motor response interferes with the binding of object identity and object position in iconic memory, then we expected that the participants would make more mislocation errors and have fewer correct responses at the 50 -msec cue delay for trials in the buttonpress condition than in the single-task (i.e., no-buttonpress) condition. However, if blinks are unique in their capacity to disrupt cognitive processing, then we expected that there would be no difference in performance between the single- and dual-task conditions of Experiment 3.

\section{Method}

Participants. Ten students at the University of Illinois participated in one experimental session approximately $60 \mathrm{~min}$ long. All the participants reported normal or corrected-to-normal vision, were naive with respect to the experimental hypotheses, and had not participated in Experiment 1 or Experiment 2. They received $\$ 6$ per hour for their participation.

Stimuli and Apparatus. The stimuli and apparatus for Experiment 3 were identical to those described for Experiment 1. The participants made their buttonpress responses with a handheld response device interfaced with the computer.
Procedure. Trials in the no-buttonpress single-task condition were identical to the no-blink trials of Experiment 1. Buttonpress trials followed the same course of events as the blink trials used in Experiment 1; however, instead of being instructed to blink as soon as the letter array appeared, the participants in Experiment 3 were asked to press a button with the right thumb when they saw the letter array. Because the participants needed to hold the response device, it was no longer practical for them to use the computer keyboard for trial initiation or to type in their partial-report response. Thus, to initiate each trial, the participants pressed the left thumb key on the handheld device instead of the "Return" key on the keyboard. Instead of typing their partial-report responses, the participants verbally reported their responses to a lab assistant, who entered them with the keyboard. In order to avoid miscommunication errors between participant and assistant, the typed responses still appeared in the response box on the computer screen in front of the participant. The participant had to confirm that the intended string of letters was present before the assistant pressed the "Return" key to finalize the response.

Design. The design of Experiment 3 was identical to the design of Experiment 1, including the same practice conditions and counterbalancing. Two participants failed to meet the partial report accuracy criteria described in Experiment 1, were dropped from the study, and were replaced.

\section{Results and Discussion}

Any trials in which a participant blinked were eliminated from analyses, as were trials in which a participant failed to follow instructions regarding whether or not to make a buttonpress response; buttonpress trials in which the response was made before array offset or in which the buttonpress latency was greater than $500 \mathrm{msec}$ were also discarded. A total of $0 \%$ of the no-buttonpress trials and a total of $29.3 \%$ of the buttonpress trials were discarded; the vast majority of the discarded trials were due to the participants' executing buttonpresses before array offset. For the remaining trials, the mean buttonpress latencies were $199 \mathrm{msec}$ at the 50-msec cue delay, $197 \mathrm{msec}$ at the 150 -msec cue delay, and $199 \mathrm{msec}$ at the $750-\mathrm{msec}$ cue delay. These latencies did not differ from each other $[F(2,18)<1]$. The mean buttonpress durations were $201 \mathrm{msec}$ at the 50 -msec cue delay, $186 \mathrm{msec}$ at the 150 -msec cue delay, and $200 \mathrm{msec}$ at the $750-\mathrm{msec}$ cue delay. These durations were not significantly different from each other $[F(2,18)=1.1$, $\left.M S_{\mathrm{e}}=598, p>.3\right]$.

Figure 6 shows the mean percentage of correct responses, mislocation errors, and intrusion errors as a function of cue delay for the buttonpress and no-buttonpress conditions. Not surprisingly, this figure shows the typical trend of decreasing accuracy (increasing error rate) as cue delay increases. Two-way ANOVAs with factors of condition (no-buttonpress vs. buttonpress) and cue delay indicated that this main effect of cue delay was significant in all cases [for correct responses, $F(2,18)=34.8, M S_{\mathrm{e}}=$ $0.005, p<.001$; for mislocation errors, $F(2,18)=25.0$, $M S_{\mathrm{e}}=0.004, p<.001$; for intrusion errors, $F(2,18)=$ $\left.7.0, M S_{\mathrm{e}}=0.002, p=.006\right]$.

The primary question of interest was whether partialreport performance would differ between the no-buttonpress and buttonpress conditions. As can be seen from Figure 6, the participants made an equal number of correct responses, mislocation errors, and intrusion errors in the buttonpress condition as in the no-buttonpress condition 


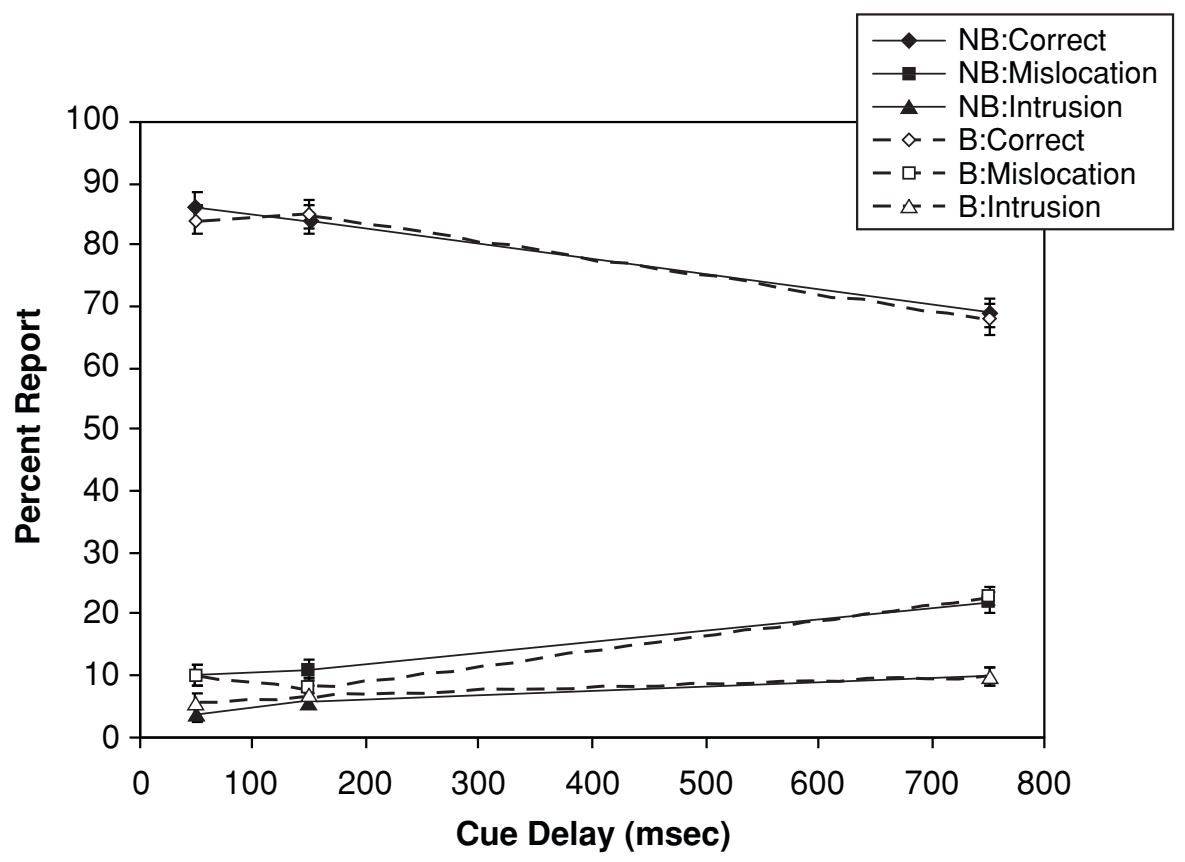

Figure 6. Mean percentages of correct responses, mislocation errors, and intrusion errors as a function of cue delay for no-buttonpress (NB) and buttonpress (B) trials in Experiment 3.

(all condition main effects and condition $\times$ cue delay interactions, $p>.5$ ). Unlike in the blink condition of Experiment 1 , there was no reduction in accuracy or increase in mislocation errors at a cue delay of $50 \mathrm{msec}$ in the buttonpress condition relative to the no-buttonpress condition. These results show that, unlike performing an eyeblink, pressing a button does not interfere with the binding of object position with object identity in iconic memory. Thus, Experiment 3 demonstrated that not every motor response disrupts partial-report performance, suggesting that the performance decrement associated with blinking that was found in Experiment 1 was not the result of general motoric dual-task interference.

One potential problem with this conclusion is that the latency and the duration of the buttonpresses in Experiment 3 were on average somewhat shorter than the mean blink latencies and the mean blink durations in Experiment 1. Several additional analyses were conducted to investigate whether these differences might have produced the differences in partial report performance between the two experiments. First, a between-experiments ANOVA showed that mean buttonpress latency (198 msec) in Experiment 3 did not differ significantly from mean blink latency $(225 \mathrm{msec})$ in Experiment $1\left[F(1,20)=2.56, M S_{\mathrm{e}}=4,508, p>.12\right]$. However, the difference approached significance, so a median split was conducted on the blink latencies in Experiment 1 , and the results for the short-latency blink trials were compared with those for the long-latency blink trials (see Figure 7). Mean blink latency on the short-latency trials was $185 \mathrm{msec}$, whereas mean blink latency on the long-latency trials was $267 \mathrm{msec}$. These values bracket the value for mean buttonpress latency in Experiment 3.
ANOVAs conducted on correct reports, mislocation errors, and intrusion errors using blink latency (short vs. long) as a factor found that neither accuracy nor error patterns differed as a function of blink latency (all $F_{\mathrm{s}}<1$ ). Accuracy at the 50-msec cue delay for the short-latency blink trials (i.e., those whose latency was most similar to buttonpress latency) was actually somewhat worse (64.2\%) than for the long-latency blink trials $(70.2 \%)$, but this difference was not significant. In sum, these analyses suggest that the differential effects of blinks and buttonpresses were not due to differences in response latency.

Similar analyses were conducted to determine whether differences in response duration, rather than response latency, might have led to the differences in response accuracy across the two experiments. First, a betweenexperiments ANOVA showed that mean buttonpress duration (196 msec) in Experiment 3 did not differ significantly from mean blink duration $(265 \mathrm{msec})$ in Experiment $1\left[F(1,20)=2.77, M S_{\mathrm{e}}=28,024, p>.10\right]$. However, the difference was quite large and approached significance, so a median split was conducted on the blink durations in Experiment 1, and the results for the shortduration blink trials were compared with those for the longduration blink trials (see Figure 8). Mean blink duration on the short-duration trials was $184 \mathrm{msec}$, whereas mean blink duration on the long-duration trials was $339 \mathrm{msec}$. These values bracket the value for mean buttonpress duration in Experiment 3. ANOVAs conducted on correct reports, mislocation errors, and intrusion errors using blink duration (short vs. long) as a factor found that neither accuracy nor error patterns differed as a function of blink duration (all $F_{\mathrm{S}}<1$ ). Thus, these analyses suggest that 


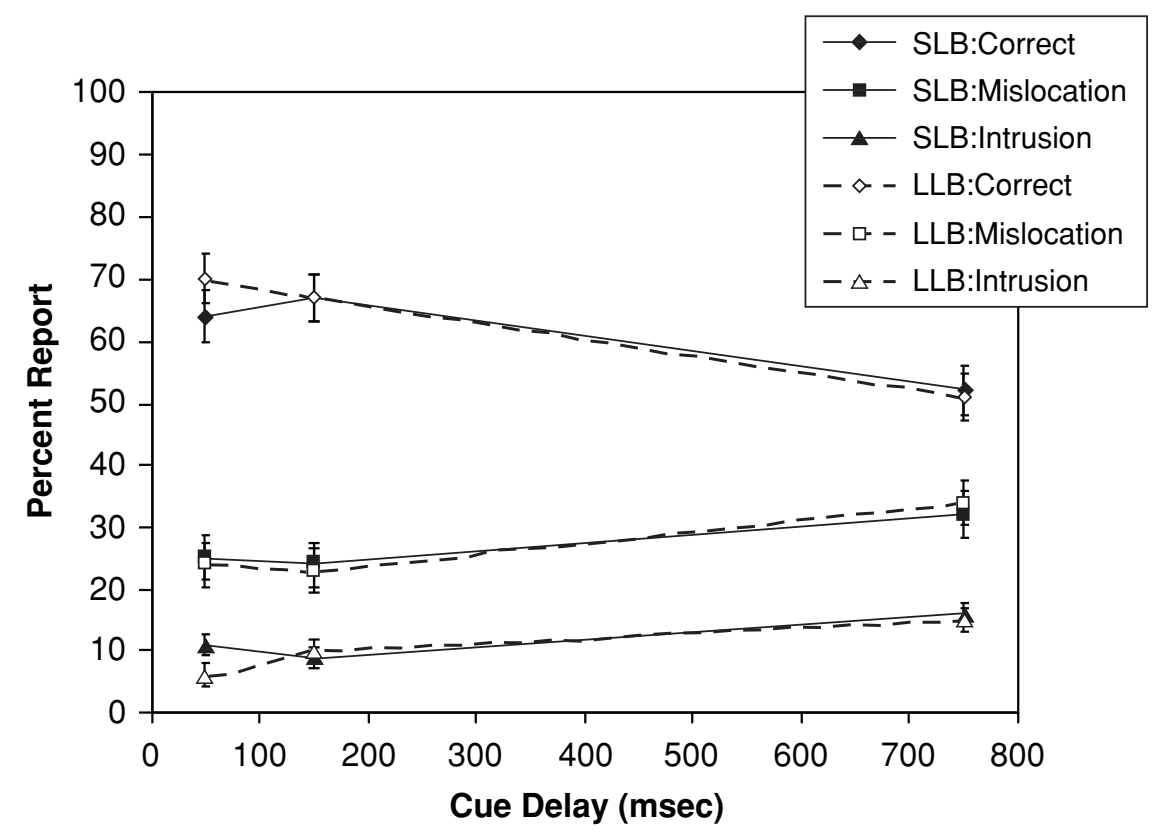

Figure 7. Mean percentages of correct responses, mislocation errors, and intrusion errors as a function of cue delay for short-latency blink (SLB) and long-latency blink (LLB) trials in Experiment 1.

the differential effects of blinks and buttonpresses were not due to differences in blink duration, either.

In sum, although the latency and the duration of blinks in Experiment 1 were somewhat different from the latency and the duration of buttonpresses in Experiment 3, these differences do not appear to account for the differences in partial-report performance between the two experiments. Experiment 3 thus demonstrated that not all motor

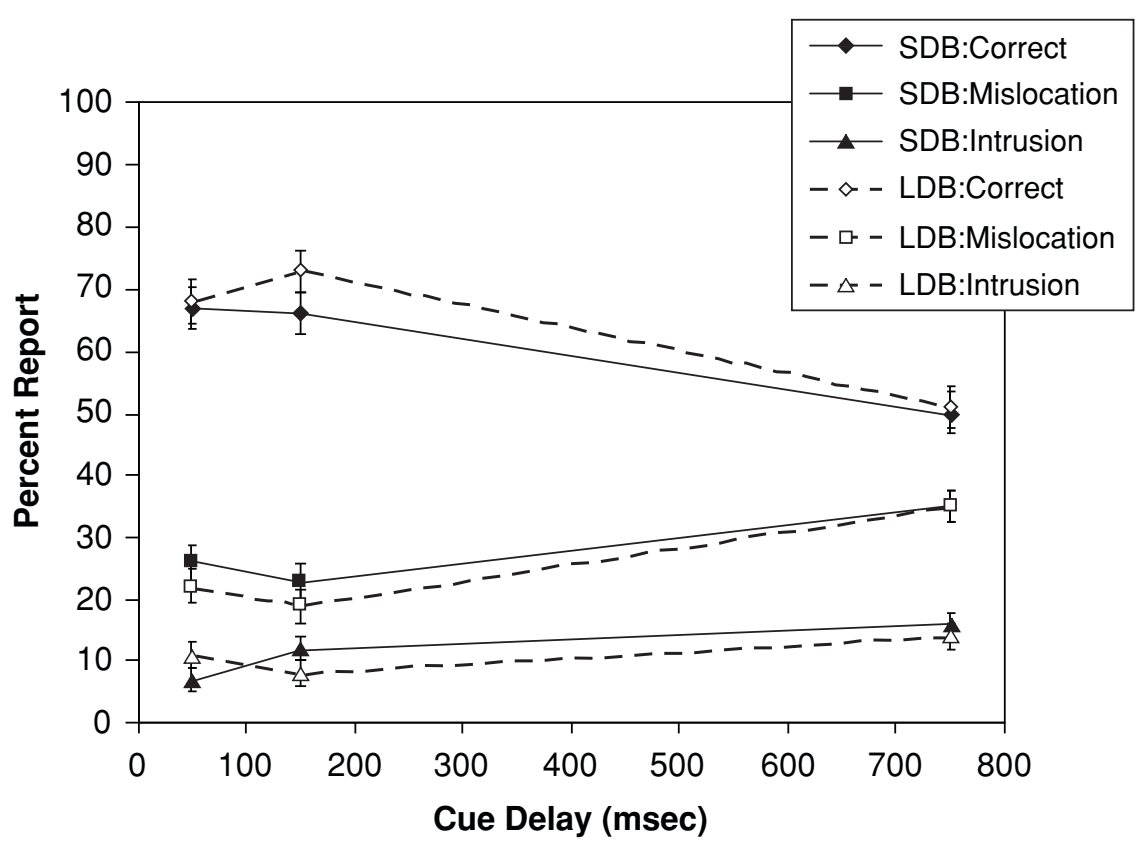

Figure 8. Mean percentages of correct responses, mislocation errors, and intrusion errors as a function of cue delay for short-duration blink (SDB) and long-duration blink (LDB) trials in Experiment 1. 
responses cause interference in the partial-report task, suggesting that blinks may be unique in their ability to disrupt iconic memory. However, one might argue that blinks and buttonpresses are not very similar to each other (although a buttonpress might be thought of as a "finger blink"). Therefore, in Experiment 4, we examined this issue further by using a motor response more similar to an eye blink - namely, an eye closure. That is, in Experiment 4 , the participants were instructed to close their eyes when the letter array appeared and to keep them closed until after they heard the response cue. Closing the eyes is similar to blinking them, except for being less transient in nature. Another virtue of using this response is that the latency of eye closures is similar to that of eye blinks, simplifying comparisons across the two types of responses.

\section{EXPERIMENT 4}

In Experiment 4, we examined the effect closing the eyes had on partial-report performance. The participants again performed the standard partial-report task under both single- and dual-task conditions. In this case, for the dualtask condition, the participants were instructed to close their eyes as soon as the letter array appeared and not to open them until after they heard the cue tone. If closing the eyes is sufficient to cause iconic memory interference, then the participants were expected to perform more poorly in the dual-task condition than in the single-task condition at the shortest cue delay, just as they did in Experiment 1 . No differences between performance in eyesclosed and eyes-open conditions would indicate that the partial-report interference observed in Experiment 1 was the result of mechanisms linked specifically to blinking.

\begin{abstract}
Method
Participants. Ten students at the University of Illinois participated in one experimental session approximately $60 \mathrm{~min}$ long. All participants reported normal or corrected-to-normal vision, were naive with respect to the experimental hypotheses, and had not participated in Experiment 1, Experiment 2, or Experiment 3. They received $\$ 6$ per hour for their participation.

Stimuli and Apparatus. The stimuli and apparatus were identical to the ones used in Experiment 1.

Procedure. The procedure of Experiment 4 was the same as that of Experiment 1 with one exception: for the dual-task eyes-closed condition, the participants were told to close their eyes as soon as they saw the array and not to open their eyes again until after the cue tone was sounded.

Design. The design of Experiment 4 was identical to the design of Experiment 1; practice and data collection blocks included the same number of trials and counterbalancing as in the earlier experiment.
\end{abstract}

\section{Results and Discussion}

Trials in which a participant did not follow the eyesclosed/eyes-open instructions were not included in the analyses; eyes-closed trials in which the closure was initiated before array offset or had a latency of over $500 \mathrm{msec}$ were also discarded from the analyses. A total of 5.3\% of the eyes-open trials and $14.2 \%$ of the eyes-closed trials were discarded. For the remaining eyes-closed trials, the mean latencies for closing the eyes were $224 \mathrm{msec}$ when the cue delay was $50 \mathrm{msec}, 233 \mathrm{msec}$ when the cue delay was $150 \mathrm{msec}$, and $251 \mathrm{msec}$ when the cue delay was $750 \mathrm{msec}$. The main effect of cue delay was significant $\left[F(2,18)=5.5, M S_{\mathrm{e}}=336, p<.02\right]$; on the basis of a Scheffé 95\% confidence interval, pairwise differences greater than $21.8 \mathrm{msec}$ were significant, so latency was longer when the cue delay was $750 \mathrm{msec}$ than when it was $50 \mathrm{msec}$. Since the participants did not know from one trial to the next what the cue delay would be and since the eye closure must have been programmed well in advance of tone onset, it seems unlikely that this effect has much psychological significance. Furthermore, the median-split analyses conducted on the data of Experiment 1 suggest that variations in latency have little effect on performance. A between-experiments ANOVA showed that mean eyeclosing latency $(236 \mathrm{msec})$ in Experiment 4 did not differ significantly from mean blink latency $(225 \mathrm{msec})$ in Experiment $1\left[F(1,20)=0.3, M S_{\mathrm{e}}=6,854, p>.55\right]$. Not surprisingly, the durations of eye closures in Experiment 4 were considerably longer than the blink durations in Experiment 1; the mean durations for keeping the eyes closed were $820 \mathrm{msec}$ when the cue delay was $50 \mathrm{msec}, 876 \mathrm{msec}$ when the cue delay was $150 \mathrm{msec}$, and $1,265 \mathrm{msec}$ when the cue delay was $750 \mathrm{msec}[F(2,18)=$ $\left.29.9, M S_{\mathrm{e}}=19,600, p<.001\right]$.

Figure 9 shows the mean number of correct responses, mislocation errors, and intrusion errors for the eyes-open and eyes-closed conditions at each of the three cue delays. As in the previous experiments, Figure 9 shows the standard pattern of decreasing accuracy as a function of increasing cue delay. As was the case for Experiments 1, 2 , and 3, separate two-way ANOVAs with factors of condition (eyes open vs. eyes closed) and cue delay indicated that the main effect of cue delay was significant for each dependent measure [for correct responses, $F(2,18)=$ $43.3, M S_{\mathrm{e}}=0.006, p<.001$; for mislocation errors, $F(2,18)=28.2, M S_{\mathrm{e}}=0.003, p<.001$; for intrusion errors, $\left.F(2,18)=26.4, M S_{\mathrm{e}}=0.001, p<.001\right]$.

The second and most relevant point to be made about Figure 9 is that it shows almost no difference for correct responses and errors between the eyes-open and eyes-closed conditions $(p>.2$, for all condition main effects and condition $\times$ cue delay interaction). This indicates that the participants had no more difficulty performing the partialreport task with their eyes closed than they did when their eyes were open. More specifically, the lack of difference in mislocation errors at the shortest cue delay across conditions indicates that, unlike blinking, closing one's eyes and keeping them closed does not lead to difficulties in binding object position and object identity in iconic memory. This result supports our earlier claim that blinks may be unique in their ability to interfere with partial-report performance. The results of Experiment 4 also lend support to the conclusion that the differences in performance across Experiments 1 and 3 were not due to differences in motor response latency or duration. Buttonpresses in Experiment 3 had shorter latencies and durations than did blinks in Experiment 1, but eye closures in Experiment 4 had slightly longer latencies and considerably longer durations; but only 


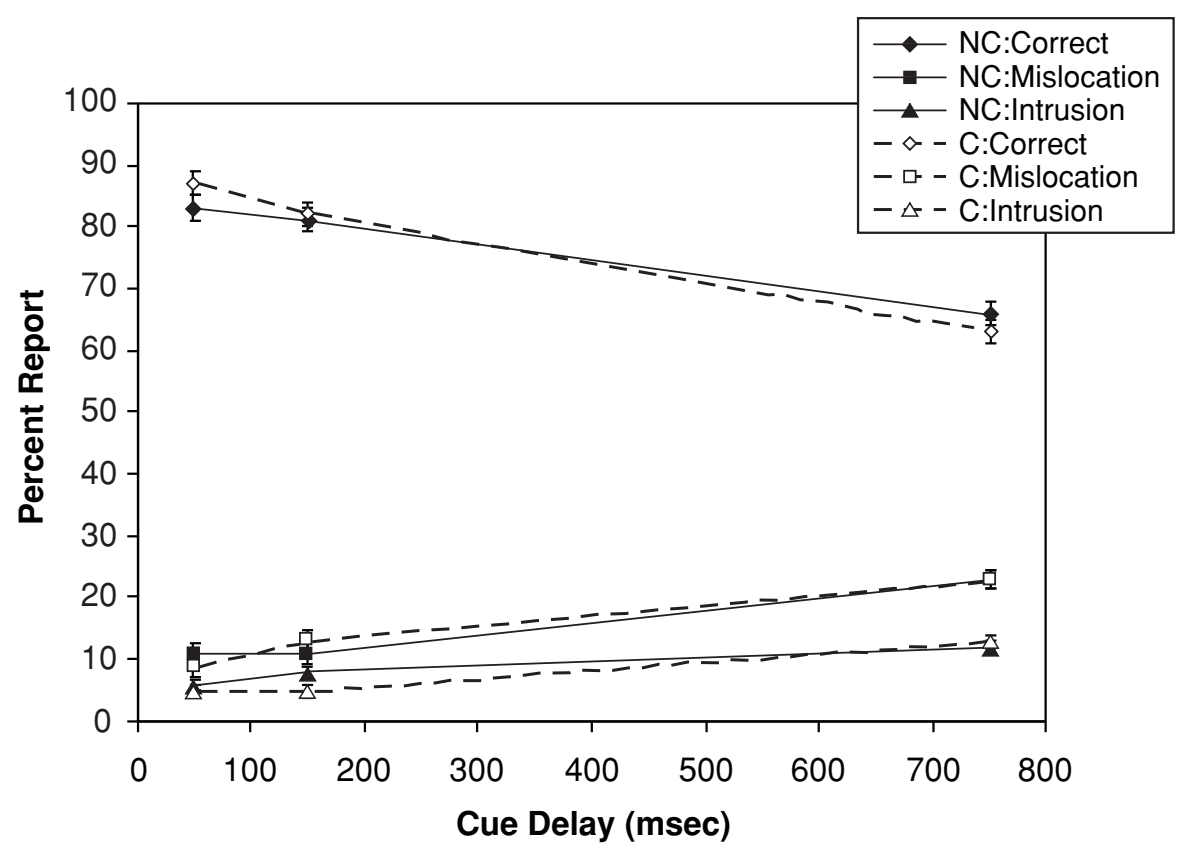

Figure 9. Mean percentages of correct responses, mislocation errors, and intrusion errors as a function of cue delay for eyes-open (NC) and eyes-closed (C) trials in Experiment 4.

eyeblinks, and not buttonpresses or eye closures, interfered with iconic memory. We conclude that blinks are special in their disruptive effects on partial-report performance.

\section{GENERAL DISCUSSION}

The present research provided evidence that eyeblinks can interfere with cognitive processing, a new phenomenon we call cognitive blink suppression. In Experiment 1 , the participants performed a partial-report iconic memory task under blink and no-blink conditions. Accuracy was lower and the participants made significantly more mislocation errors under the blink condition than under the no-blink condition when the delay between the offset of the to-be-reported letter array and the cue tone was very short. However, there were no differences between the number of intrusion errors in each condition, nor did blinking disrupt partial-report performance at the longer cue delays. These results suggest that performing an eyeblink interferes with the storage or the retrieval of information from iconic memory, disrupting the binding of object identity with object position. Experiment 2 showed that this interference was not due to visual events surrounding eyeblinks but was due to something specific to eyeblinks per se. Experiment 3 showed that not every motor response has this disruptive effect on iconic memory performance; pressing a button instead of blinking did not interfere with the partial-report task. Experiment 4 generalized this result, showing that not all eye closures disrupt iconic memory. Taken together, the results of these experiments suggest that blinks are unique in their ability to interfere with iconic memory.
Why might blinks interfere with iconic memory? Experiment 2 showed that fluctuations in light intensity that are similar to those produced by an eyeblink do not interfere with partial-report performance in the absence of an eyeblink. However, it is still possible that eyeblinks themselves (i.e., the movement of the eyelids across the eye) might cause visual masking. If blinks act as masks, they must be relatively weak ones; previous studies investigating the effects of masks on partial-report performance have often shown that the icon is completely eliminated by the mask, so that accuracy at all cue delays is no better than what short-term memory allows. In Experiment 1, however, blinks interfered with performance only at the 50-msec cue delay and did not completely eliminate the icon; that is, even in the blink condition, accuracy at cue delays of 50 and $150 \mathrm{msec}$ was higher than accuracy at the 750-msec cue delay, indicating that some information survived the blink. What blinks did in Experiment 1 was reduce performance at the 50-msec cue delay to a level equivalent to that found at the 150 -msec cue delay.

The hypothesis that blinks exert their effect on performance via masking is consistent with physiological evidence regarding the locus of iconic memory and of the neural activity associated with blinks. Several studies have shown that visual information persists in primary visual cortex (V1) after display offset (e.g., Duysens, Orban, Cremieux, \& Maes, 1985; Engel, 1970; Supèr, Spekreijse, $\&$ Lamme, 2001). However, blinks suppress the activity of neurons in V1 (Gawne \& Martin, 2000), so in the process they presumably interfere with the representation in iconic memory. Thus, the suppression of iconic memory by blinks that was observed in the present research might have 
been the result of neural interference in V1. This hypothesis is consistent with the proposal that transient responses in V1 cortical neurons are correlated with forward- and backward-masking phenomena (Macknik \& Livingstone, 1998).

Another possibility, however, is that blinks may exert their effect, at least in part, on higher levels of the visual/ cognitive processing stream. In addition to V1, activation in posterior parietal cortex has also been shown to be affected by blinks (Bodis-Wollner, Bucher, \& Seelos, 1999; Hari, Salmelin, Tissari, Kajola, \& Virsu, 1994); this area is thought to be an essential part of the spatial working memory system (e.g., Awh et al., 1999; D’Esposito et al., 1998; Jonides et al., 1993). Because blinks appear to selectively interfere with position information rather than identity information, it seems possible that the deleterious effects of blinks occur at this level rather than at the level of V1. We plan to investigate this further in future research.

Although the present research suggests that the disruptive effect of blinking on partial-report performance is unique, one other motor response has also been shown to interfere with iconic memory-namely, saccadic eye movement (Irwin, 1992). The similarities between blinks and saccades are numerous. Visual suppression due to blinking is mirrored by a similar phenomenon in which visual sensitivity is reduced during saccades. This phenomenon is termed visual saccadic suppression (Matin, 1974; Volkmann, 1986; Zuber \& Stark, 1966). Several studies have suggested that saccadic suppression and blink suppression are the result of the same neural mechanisms (Ridder \& Tomlinson, 1995, 1997; Uchikawa \& Sato, 1995; Volkmann, 1986). In addition, recent investigations have shown that saccades interfere with some cognitive processes as well, particularly those that involve visuospatial processing (for a review, see Irwin, 2003). In future research, we plan to investigate whether cognitive saccadic suppression and cognitive blink suppression rely on the same underlying mechanisms.

In conclusion, the present research provides evidence for a new phenomenon, cognitive blink suppression, in which certain processes are disrupted when performed in tandem with a blink. Specifically, blinking interferes with the binding of object position and object identity in iconic memory. This disruption in iconic memory may be the result of neural interference; the suppression of cortical neurons during blinks may suppress iconic memory representations that rely on the same areas of the brain.

\section{REFERENCES}

Averbach, E., \& Coriell, A. S. (1961). Short-term memory in vision. Bell System Technical Journal, 40, 309-328.

Awh, E., Jonides, J., Smith, E., Buxton, R., Frank, L., Love, T., ET AL. (1999). Rehearsal in spatial working memory: Evidence from neuroimaging. Psychological Science, 10, 433-437.

Baumstimler, Y., \& PARRot, J. (1971). Stimulus generalization and spontaneous blinking in man involved in a voluntary activity. Journal of Experimental Psychology, 88, 95-102.

Bodis-Wollner, I., Bucher, S. F., \& Seelos, K. C. (1999). Cortical activation patterns during voluntary blinks and voluntary saccades. Neurology, 53, 1800-1805.
Brockmole, J. R., Carlson, L. A., \& Irwin, D. E. (2002). Inhibition of attended processing during saccadic eye movements. Perception \& Psychophysics, 64, 867-881.

Coltheart, M. (1980). Iconic memory and visible persistence. Perception \& Psychophysics, 27, 183-228.

D’Esposito, M., Aguirre, G., Zarahn, E., Ballard, D., Shin, R., \& LEASE, J. (1998). Functional MRI studies of spatial and nonspatial working memory. Cognitive Brain Research, 7, 1-13.

DicK, A. O. (1969). Relations between the sensory register and shortterm storage in tachistoscopic recognition. Journal of Experimental Psychology, 82, 279-284.

Di Lollo, V. (1978). On the spatiotemporal interactions of brief visual displays. In R. H. Day \& G. V. Stanley (Eds.), Studies in perception (pp. 39-55). Perth: University of Western Australia Press.

DREW, G. C. (1951). Variations in reflex blink-rate during visual-motor tasks. Quarterly Journal of Experimental Psychology, 3, 73-88.

Duysens, J., Orban, G. A., Cremieux, J., \& Maes, H. (1985). Visual cortical correlates of visible persistence. Vision Research, 25, 171178.

ENGEL, G. R. (1970). An investigation of visual responses to brief stereoscopic stimuli. Quarterly Journal of Experimental Psychology, 22, 148-166.

FogarTy, C., \& STERn, J. A. (1989). Eye movements and blinks: Their relationship to higher cognitive processes. International Journal of Psychophysiology, 8, 35-42.

Gawne, T. J., \& Martin, J. M. (2000). Activity of primate V1 cortical neurons during blinks. Journal of Neurophysiology, 84, 2691-2694.

Hari, R., Salmelin, R., Tissari, S. O., Kajola, M., \& Virsu, V. (1994). Visual stability during eyeblinks. Nature, 367, 121-122.

IRWIN, D. E. (1992). Memory for position and identity across eye movements. Journal of Experimental Psychology: Learning, Memory, \& Cognition, 18, 307-317.

IRWIN, D. E. (2003). Eye movements and visual cognitive suppression. In B. H. Ross \& D. E. Irwin (Eds.), Cognitive vision (Psychology of Learning and Motivation, Vol. 42, pp. 265-293). San Diego: Academic Press.

IrWIN, D. E., \& BRocKmole, J. R. (2000). Mental rotation is suppressed during saccadic eye movements. Psychonomic Bulletin \& Review, 7, 654-661.

Irwin, D. E., \& Brockmole, J. R. (2004). Suppressing where but not what: The effect of saccades on dorsal- and ventral-stream visual processing. Psychological Science, 15, 467-473.

IrWIN, D. E., \& BROWN, J. S. (1987). Tests of a model of informational persistence. Canadian Journal of Psychology, 41, 317-338.

Irwin, D. E., \& Carlson-Radvansky, L. A. (1996). Suppression of cognitive activity during saccadic eye movements. Psychological Science, 7, 83-88.

Irwin, D. E., \& Yeomans, J. M. (1986). Sensory registration and informational persistence. Journal of Experimental Psychology: Human Perception \& Performance, 12, 343-360.

Jonides, J., Smith, E., Koeppe, R., Awh, E., Minoshima, S., \& MinTUN, M. (1993). Spatial working memory in humans as revealed by PET. Nature, 363, 623-625.

Kennard, D. W., \& Glaser, G. H. (1964). An analysis of eyelid movements. Journal of Nervous \& Mental Disease, 139, 31-48.

Loftus, G. R., \& IRwIN, D. E. (1998). On the relations among different measures of visible and informational persistence. Cognitive Psychology, 35, 135-199.

MaCKNiK, S. L., \& Livingstone, M. S. (1998). Neuronal correlates of visibility and invisibility in the primate visual system. Nature Neuroscience, 1, 144-149.

Matin, E. (1974). Saccadic suppression: A review and an analysis. Psychological Bulletin, 81, 899-917.

Mewhort, D. J. K., Campbell, A. J., Marchetti, F. M., \& Campbell, J. I. D. (1981). Identification, localization, and "iconic" memory: An evaluation of the bar-probe task. Memory \& Cognition, 9, 50-67.

NeISSER, U. (1967). Cognitive psychology. New York: Appleton-CenturyCrofts.

Ridder, W. H., \& TomLinson, A. (1995). Spectral characteristics of blink suppression in normal observers. Vision Research, 35, 25692578. 
RidDer, W. H., \& Tomlinson, A. (1997). A comparison of saccadic and blink suppression in normal observers. Vision Research, 37, 3171 3179.

Riggs, L. A., Volkmann, F. C., \& Moore, R. K. (1981). Suppression of the blackout due to blinks. Vision Research, 21, 1075-1079.

SperLing, G. (1960). The information available in brief visual presentations. Psychological Monographs, 74, 1-29.

Sperling, G. (1963). A model for visual memory tasks. Human Factors, 5, 19-31.

Stern, J. A., \& Skelly, J. J. (1984). The eye blink and workload consideration. Proceedings of the Human Factors Society, 28, 942-944.

Stern, J. A., Walrath, L. C., \& Goldstein, R. (1984). The endogenous eyeblink. Psychophysiology, 21, 22-23.

Supèr, H., Spekreisse, H., \& LAmme, V. (2001). A neural correlate of working memory in the monkey primary visual cortex. Science, 293, 120-124.
TownsEnd, V. M. (1973). Loss of spatial and identity information following a tachistoscopic exposure. Journal of Experimental Psychology, 98, 113-118.

UCHIKAWA, K., \& SATO, M. (1995). Saccadic suppression of achromatic and chromatic responses measured by increment-threshold spectral sensitivity. Journal of the Optical Society of America A, 12, 661-666.

VolKmann, F. C. (1986). Human visual suppression. Vision Research, 26, 1401-1416.

Volkmann, F. C., Riggs, L. A., \& Moore, R. K. (1980). Eyeblinks and visual suppression. Science, 207, 900-902.

Zuber, B. L., \& StARK, L. (1966). Saccadic suppression: Elevation of visual threshold associated with saccadic eye movements. Experimental Neurology, 16, 65-79.

(Manuscript received March 3, 2004; revision accepted for publication June 20, 2005.) 